Article

\title{
Reactivity and Heavy Metal Removal Capacity of Calcium Alginate Beads Loaded with Ca-Al Layered Double Hydroxides
}

\author{
Andres Borgiallo and Ricardo Rojas *(1) \\ INFIQC-CONICET, Departamento de Fisicoquímica, Facultad de Ciencias Químicas, Universidad Nacional de \\ Córdoba, Ciudad Universitaria, 5000 Córdoba, Argentina; andyborgy.94@gmail.com \\ * Correspondence: rrojas@fcq.unc.edu.ar
}

Received: 13 January 2019; Accepted: 27 February 2019; Published: 1 March 2019

check for updates

\begin{abstract}
Layered double hydroxides (LDHs) present multiple applications due to their versatility and reactivity. Thus, Ca-Al LDHs with Friedel's salt structure (HC) have been proposed as heavy metal scavengers due to their buffering capacity at basic pHs. Nevertheless, the control of the reactivity of LDHs such as $\mathrm{HC}$ is necessary to optimize their applications. Here, the reactivity of an $\mathrm{HC}$ prepared by a coprecipitation method was modified by its inclusion in calcium alginate $(\mathrm{CaAlg})$ beads prepared by ionic gelation. The obtained beads $(\mathrm{CaAlg} / \mathrm{HC})$ showed good dispersion of the $\mathrm{HC}$ particles in the alginate matrix and were used to test the acid base reactivity and heavy metal uptake capacity compared with pure CaAlg beads and HC powder separately. The $\mathrm{pH}$ buffering capacity of CaAlg beads was enriched by the inclusion of HC that, in turn, was modulated in its reactivity. Thus, the HC dissolution times changed from mere seconds for the powder to tens of minutes when enclosed in the beads in a kinetic profile determined by the diffusive step. On the other hand, $\mathrm{Cu}^{2+}$ uptake capacity of $\mathrm{CaAlg} / \mathrm{HC}$ beads combined the $\mathrm{Cu}(\mathrm{OH})_{2}$ precipitation capacity of $\mathrm{HC}$ with the complexation capacity of alginate, reaching good affinity and capacity for the obtained beads. Nevertheless, the precipitation of the hydroxide was produced outside the bead, which would induce the addition of an additional separation step to produce an acceptable $\mathrm{Cu}^{2+}$ elimination.
\end{abstract}

Keywords: hydrocalumite; $\mathrm{pH}$ buffering; chelation; precipitation; ionic gelation

\section{Introduction}

The combination of natural polymers and inorganic materials has drawn considerable attention due to the unique properties of the composite materials obtained, which makes them attractive in applications as packaging films, scaffolds, filters, etc. Thus, the combination of layered double hydroxides (LDHs) with hydrogels is a promising tool to enhance the properties of both components of the obtained composite, finding applications in the environmental and pharmaceutical areas, among others [1-3]. Among them, inclusion of LDHs in alginate beads has been extensively studied for environmental remediation, allowing an easy separation from the aquatic medium while providing a modulation of this solid reactivity [4].

Alginic acid is a natural, linear polymer that can be described as homopolymeric blocks formed of D-mannuronate and L-guluronate units. It portrays a large content of carboxylic groups, mainly deprotonated at neutral $\mathrm{pH}$, and the interaction with $\mathrm{Ca}^{2+}$ ions leads to the crosslinking of the alginate chains and the formation of a water-entrapping calcium alginate network. This process is used to form calcium alginate beads by the simple dropping of a sodium alginate solution in $\mathrm{CaCl}_{2}$ solution $[5,6]$. The presence of carboxylate groups also allows the uptake of heavy metal ions, such as $\mathrm{Cu}^{2+}, \mathrm{Pb}^{2+}$, or $\mathrm{Cd}^{2+}$, incorporated by chelation and ion exchange mechanisms $[1,7,8]$. 
Layered double hydroxides, on the other hand, have also demonstrated their capacity for heavy metal removal [9-11]. In some cases, polydentate ligands have been incorporated to provide heavy metal chelation capabilities to LDHs [12,13]. In others, the acid-base reactivity of LDHs [14], whose hydroxylated layers dissolve at a $\mathrm{pH}$ determined mainly by its composition, is used to produce the precipitation of the heavy metal hydroxides, either as a part of an LDH phase or not [15]. Among them, $\mathrm{Ca}-\mathrm{Al} \mathrm{LDHs}$ present the highest removal capacity and efficiency $[9,16,17]$. Ca-Al LDHs, as a member of the Friedel's salt group, present a structure similar to that of other LDHs, but their divalent cations are enclosed in a sevenfold coordination, the seventh position being occupied by a water molecule $[9,16]$. The most representative member of these $\mathrm{Ca}-\mathrm{Al} \mathrm{LDH}$ with Friedel's salt structure is the mineral hydrocalumite $\left(\mathrm{Ca}_{2} \mathrm{Al}(\mathrm{OH})_{6} \mathrm{Cl} \cdot 2 \mathrm{H}_{2} \mathrm{O}\right)$. These solids have not only been used for the removal of heavy metals, but also for the elimination of other pollutants, such as fluoride and arsenic [18,19].

The LDH application in heavy metal removal presents a drawback as LDHs are not easily separated from the polluted media due to their particle size [3]. In the particular case of hydrocalumite, its extreme reactivity produces its complete dissolution in mildly acidic media, leading to its deactivation [20]. A promising tool to overcome all these problems is the inclusion of LDHs in hydrogel beads of calcium alginate, which would allow an easy separation [1] while providing a protective environment to modulate the reactivity of the solids. Although the inclusion of LDHs in alginate beads for heavy metal removal applications has already been described [1,3], the effect on the reactivity of LDHs and the inclusion of Ca-Al LDHs has still not been explored.

In this work, a Ca-Al LDH with a Friedel's salt structure (HC) was synthesized and enclosed in calcium alginate ( $\mathrm{CaAlg}$ ) hydrogel beads. After their structural characterization, the acid-base reactivity of the obtained beads was determined in comparison with that of pure CaAlg beads and pure HC. Finally, the uptake capacity of the beads was explored using $\mathrm{Cu}^{2+}$ ion as a probe and the results obtained were compared to those of CaAlg and HC.

\section{Materials and Methods}

$\mathrm{CaCl}_{2}, \mathrm{AlCl}_{3} \cdot 6 \mathrm{H}_{2} \mathrm{O}$ and $\mathrm{Cu}\left(\mathrm{NO}_{3}\right) \cdot 3 \mathrm{H}_{2} \mathrm{O}$ (PA grade, Anedra $\left.{ }^{\circledR}\right), \mathrm{NaOH}$ granules and $37 \% \mathrm{w} / \mathrm{w} \mathrm{HCl}$ solution (PA grade, Cicarelli ${ }^{\circledR}$ ), and sodium alginate (Montreal, Argentina) were used. All solutions were prepared with purified water $(18 \mathrm{M} \Omega \mathrm{MilliQ}$, Millipore System) and all experiments, unless otherwise stated, were performed at room temperature.

\subsection{Synthesis of $\mathrm{Ca}-\mathrm{Al}$ Layered Double Hydroxides (HC)}

A chloride intercalated $\mathrm{Ca}-\mathrm{Al}$ layered double hydroxide with a Friedel's salt structure was synthesized as follows. A $0.2 \mathrm{~mol} \cdot \mathrm{L}^{-1} \mathrm{CaCl}_{2}, 0.1 \mathrm{~mol} \cdot \mathrm{L}^{-1} \mathrm{AlCl}_{3} \cdot 6 \mathrm{H}_{2} \mathrm{O}$ solution $(200 \mathrm{~mL})$ was quickly added to a $200 \mathrm{~mL}$ solution containing $0.02 \mathrm{~mol} \mathrm{NaCl}$ and $0.12 \mathrm{~mol} \mathrm{NaOH}$ under vigorous agitation provided by a Ultraturrax T18 BASIC agitator at $25000 \mathrm{rpm}$. After the addition, the obtained solid (HC) was separated by centrifugation, washed three times with water, and finally dried at $60^{\circ} \mathrm{C}$.

\subsection{Calcium Alginate Beads (CaAlg and CaAlg/HC) Preparation}

A stock $2.50 \%(\mathrm{w} / \mathrm{w})$ sodium alginate $(\mathrm{NaAlg})$ solution was prepared under agitation and heating. Once the polymer was completely dissolved, pure alginate beads (AlgCa) were prepared by dropping a solution of $1.25 \% \mathrm{NaAlg}$, using a Pasteur pipette, in a $0.02 \mathrm{~mol} \cdot \mathrm{L}^{-1} \mathrm{CaCl}_{2}$ solution under gentle magnetic stirring. The obtained beads were equilibrated for 1 hour and then separated and washed. To obtain the HC-containing calcium alginate beads (AlgCa/HC), $10 \mathrm{~mL}$ of the $2.50 \%$ NaAlg stock solution was added to $10 \mathrm{~mL}$ of a $10 \mathrm{~g} \cdot \mathrm{L}^{-1} \mathrm{HC}$ dispersion under vigorous stirring with the Ultraturrax T25 apparatus described above. This dispersion was immediately dropped into the $\mathrm{CaCl}_{2}$ solution and the formed beads were equilibrated for 1 hour and then separated, washed with water, and stored. A portion of both CaAlg and $\mathrm{CaAlg} / \mathrm{HC}$ beads were dried at $60^{\circ} \mathrm{C}$ to perform the structural characterization. 


\subsection{Structural Characterization}

Powder X-ray diffraction (PXRD) patterns were acquired at room temperature on an X-ray diffractometer (Phillips X'pert Pro instrument) equipped with a Pixcell 1D detector using $\mathrm{Cu} K \alpha$ radiation $(\lambda=1.5418 \AA$, tube operated at $40 \mathrm{kV}, 40 \mathrm{~mA})$. Data were collected over $2 \theta$ values from 5 to $70^{\circ}$ in continuous scan mode. Fourier transform infrared (FT-IR) spectra were measured in a Bruker IFS28 instrument using $\mathrm{KBr}$ discs (1:100 sample to $\mathrm{KBr}$ ratio). The samples were measured from 4000 to $400 \mathrm{~cm}^{-1}$ at $4 \mathrm{~cm}^{-1}$ resolution and at an accumulation of 64 scans. Thermogravimetric and differential thermal analyses TGA/DTA were performed in a Shimadzu DTG 60 instrument from room temperature to $800^{\circ} \mathrm{C}$ at $10^{\circ} \mathrm{C} / \mathrm{min}$ slope under flowing air $(75 \mathrm{~mL} / \mathrm{min})$. Scanning electron microscopy (SEM) images were obtained using an FE-SEM Sigma instrument. For HC powder, $0.05 \mathrm{~mL}$ of $0.1 \mathrm{~g} \cdot \mathrm{L}^{-1}$ dispersion of the sample was placed on the holder, which was afterwards dried at $50{ }^{\circ} \mathrm{C}$ and covered with an Au layer. In the case of the beads, they were cut in sections, then were placed on the holder and covered directly with an Au layer without drying.

\subsection{Proton Uptake Kinetics}

Next, $100 \mathrm{~mL}$ solutions with increasing $\mathrm{HCl}$ concentration $\left([\mathrm{HCl}]=0.1-1 \mathrm{mmol} \cdot \mathrm{L}^{-1}\right)$ were prepared. Once the $\mathrm{pH}$ was equilibrated, 10 beads of either $\mathrm{AlgCa}$ or $\mathrm{AlgCa} / \mathrm{HC}$ were added while the $\mathrm{pH}$ was measured at $10 \mathrm{~s}$ intervals up to $150 \mathrm{~min}$ using a Titrando 905 automatic titrator (Metrohm) controlled by Tiamo software and coupled to a Metrohm 9.0262.100 combined $\mathrm{pH}$ electrode. These experiments were also performed adding $1 \mathrm{~mL}$ of a $2.5 \mathrm{~g} \cdot \mathrm{L}^{-1} \mathrm{HC}$ dispersion instead of the beads.

The $\mathrm{pH}$ values were converted into proton uptake $\left(\Gamma_{\mathrm{H}}\right)$ values, calculated as:

$$
\begin{aligned}
& \text { For CaAlg and CaAlg/HC beads: } \Gamma_{H}=\left(10^{-\mathrm{pH} 0}-10^{\mathrm{pH}}\right) \cdot V \cdot n_{b}{ }^{-1} \\
& \text { For HC: } \Gamma_{H}=\left(10^{-\mathrm{pH} 0}-10^{-\mathrm{pH}}\right) \cdot V \cdot m^{-1}
\end{aligned}
$$

where $\mathrm{pH} 0$ and $\mathrm{pH}$ are the $\mathrm{pH}$ of the solution at $t=0$, and at a given time $t, V$ is the overall volume of the solution (the volume of the beads was neglected), while $n_{b}$ and $\mathrm{m}$ are the number of beads and the HC mass, respectively. The obtained $\Gamma_{H}$ vs $t$ curves were fitted with the zero order and the Higuchi models [21,22]. The first model considers that the determining step of a given process is a reaction at the surface of a particle, while for the Higuchi model, it is the diffusion of reactive or products.

$$
\begin{aligned}
& \text { Zero order model: } \Gamma_{H}=\Gamma_{H, 0}+k_{Z} \cdot t \\
& \text { Higuchi model: } \Gamma_{H}=\Gamma_{H, 0}+k_{D} \cdot t^{1 / 2}
\end{aligned}
$$

where $\Gamma_{H, 0}$ is the origin of coordinates and $k_{Z}$ and $k_{D}$ are the kinetic constants of the corresponding models.

\section{5. $\mathrm{Cu}^{2+}$ Removal Tests}

$\mathrm{Cu}^{2+}$ removal kinetics were studied as a function of $\mathrm{Cu}^{2+}$ concentration $\left(\left[\mathrm{Cu}^{2+}\right]\right)$. Ten beads of either $\mathrm{CaAlg}$ or $\mathrm{CaAlg} / \mathrm{HC}$ were added to $100 \mathrm{~mL}$ solutions with increasing $\mathrm{Cu}^{2+}$ concentrations $\left([\mathrm{Cu}]_{0}=0.4-17.6 \mathrm{ppm}\right)$ while the $\mathrm{pH}$ was continuously measured as previously described. After $150 \mathrm{~min}$, the solutions, together with the beads, were placed in sealed flasks and submitted to orbital agitation to complete 24 hours equilibration. A portion of the solution was separated and directly diluted 1:10 in $0.1 \mathrm{~mol} \cdot \mathrm{L}^{-1} \mathrm{HNO}_{3}$. In the case of CaAlg/HC beads, turbidity was observed in the samples and, consequently, besides the portion directly diluted in $\mathrm{HNO}_{3}$, an additional portion was taken, filtered, and finally diluted 1:10 in $\mathrm{HNO}_{3}$. Finally, in the case of $\mathrm{HC}$ powder, $1 \mathrm{~mL}$ of a $2.5 \mathrm{~g} \cdot \mathrm{L}^{-1}$ was added to $\mathrm{Cu}^{2+}$ solutions of the same concentrations and, after equilibration, a portion of the 
obtained dispersions were filtered and diluted as previously described. The $\mathrm{Cu}^{2+}$ uptake $\left(\Gamma_{\mathrm{Cu}}\right)$ for beads and HC particles was calculated, respectively, as

$$
\begin{aligned}
\Gamma_{\mathrm{Cu}} & =\left([\mathrm{Cu}]_{0}-[\mathrm{Cu}]_{\mathrm{eq}}\right) \cdot V \cdot m_{A l g}{ }^{-1} \\
\Gamma_{\mathrm{Cu}} & =\left([\mathrm{Cu}]_{0}-[\mathrm{Cu}]_{\mathrm{eq}}\right) \cdot V \cdot m_{H C}{ }^{-1}
\end{aligned}
$$

where $[\mathrm{Cu}]_{0}$ and $[\mathrm{Cu}]_{\text {eq }}$ are the $\mathrm{Cu}^{2+}$ concentration at $t=0$ and at equilibrium, respectively, $m_{A l g}$ and $m_{H C}$ the $\mathrm{Alg}$ and $\mathrm{HC}$ mass, respectively, while $V$ is the solution volume.

The Langmuir model was used to describe the curves and perform an estimation of the uptake capacity and affinity of the beads for $\mathrm{Cu}^{2+}$. The linearized form of the equation described for the model can be written as:

$$
\frac{[\mathrm{Cu}]_{e q}}{\Gamma_{\mathrm{Cu}}}=\frac{1}{K_{L} \cdot \Gamma_{\mathrm{Cu}, \max }}+\frac{[\mathrm{Cu}]_{e q}}{\Gamma_{\mathrm{Cu}, \max }}
$$

where $\Gamma_{\mathrm{Cu}}$ and $\Gamma_{\mathrm{Cu}, \max }$ are the uptake capacity at a considered concentration and the maximum uptake capacity, respectively, and $K_{L}\left(\mathrm{ppm}^{-1}\right)$ was the affinity constant. The model assumes that the uptake is produced as adsorption at the surface of a solid where a monolayer of the adsorbate is incorporated. Additionally, it is assumed that all the binding sites are of the same affinity for the adsorbate. This model, together with the Freundlich model, is commonly used to give an interpretation of the uptake behavior of alginate beads and LDHs against heavy metals $[16,17,23,24]$. Nevertheless, due to poor correspondence between the system characteristics and the basic assumptions of the Langmuir model, here it was used to allow comparison between CaAlg and CaAlg/HC beads. For the same reasons, the fitting with Freundlich model was avoided.

\section{Results}

\subsection{Structural and Morphological Characterization of CaAlg and CaAlg/HC}

The above described bead preparation methods allowed the obtaining of pure CaAlg and $\mathrm{Ca}-\mathrm{Al}$ $\mathrm{LDH}$ containing $(\mathrm{CaAlg} / \mathrm{HC})$ beads with regular sizes (Supporting Information, Figure S1): the former ones were more transparent than the latter, which showed a white shade compared to the yellowish-brown CaAlg beads. The $\mathrm{CaAlg} / \mathrm{HC}$ beads were prepared right after the $\mathrm{NaAlg} / \mathrm{HC}$ mixture was prepared, as a viscosity increase was observed with time. This effect was related to the instability of Ca-Al LDHs [9], enhanced by the high affinity of $\mathrm{NaAlg}$ for $\mathrm{Ca}^{2+}$ ions. Consequently, $\mathrm{Ca}^{2+}$ ions were released in the medium, which produced the ionic crosslinking of Alg chains and, therefore, its gelation.

The PXRD patterns of the dried beads and the HC sample are shown in Figure 1. CaAlg beads (Figure $1 \mathrm{~b}$ ) showed only small peaks corresponding to an $\mathrm{NaCl}$ phase (Joint Committee on Powder Diffraction Standards, JCPDS file 05-0628) and even the wide bands obtained for NaAlg (Figure 1a) were absent. The PXRD pattern of the HC sample (Figure 1c) showed that a single phase of a chloride intercalated LDH with a Friedel's salt structure (JCPDS database, file 31-0105, with a rhombohedral unit cell with parameters $\mathrm{c}=46.8 \AA$ and $\mathrm{a}=4.98 \AA$ ) was obtained. Contrarily to most LDH phases, the sample presented a high crystallinity, as reflected by the large number of thin, intense peaks obtained in the pattern. Upon their inclusion in CaAlg/HC beads (Figure 1d) the peaks corresponding to the HC phase diminished in intensity and, more importantly, presented a widening of the peaks. This result was indicative of an ordering loss upon incorporation with the beads and a strong interaction between the HC layers and the alginate chains. 


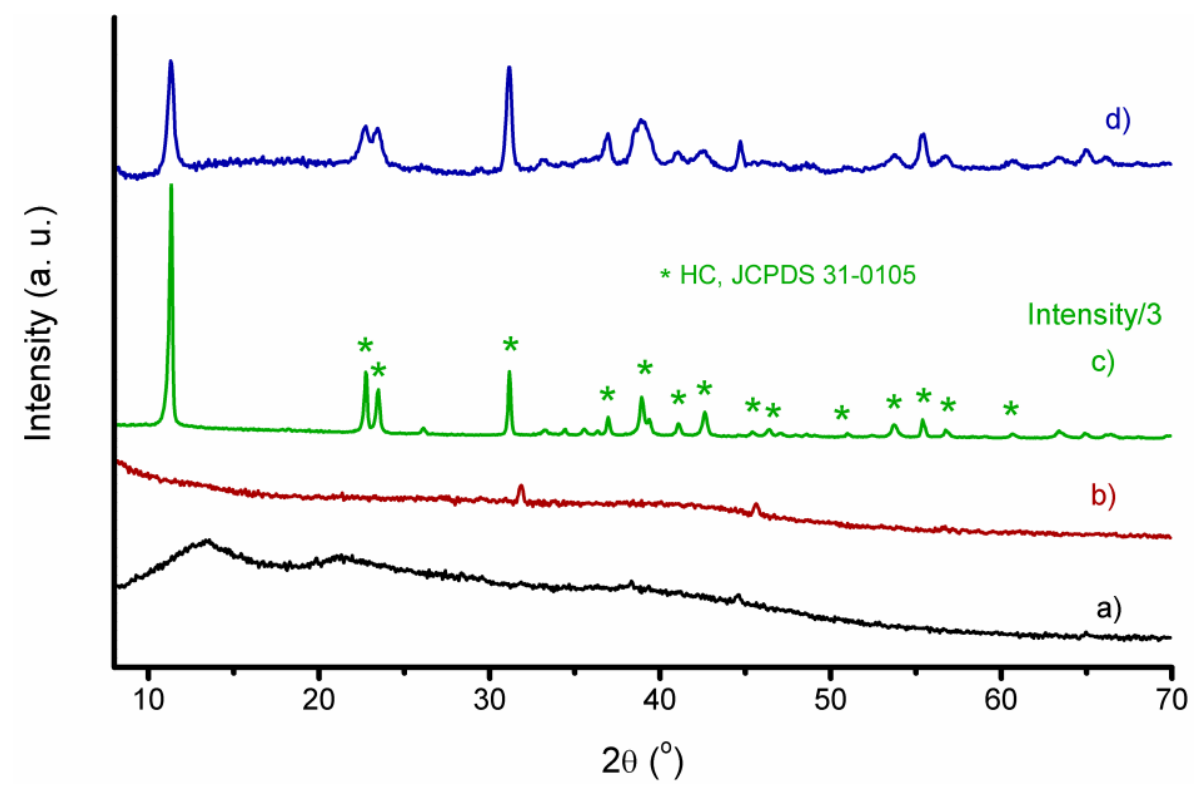

Figure 1. PXRD patterns of (a) NaAlg, (b) CaAlg beads, (c) hydrocalumite (HC), and (d) CaAlg/HC beads.

The FT-IR spectra (Figure 2) confirmed the inclusion of HC in the CaAlg beads. Both NaAlg and CaAlg showed similar bands, such as the wide band obtained at $3416-3447 \mathrm{~cm}^{-1}$, corresponding to $v_{\mathrm{OH}}$ of hydroxyl groups mannuronate and guluronate units as well as entrapped water. Bands obtained at $1610-1613$ and $1419-1427 \mathrm{~cm}^{-1}$ were attributed to $v_{\mathrm{COO}, \text { sym }}$ and $v_{\mathrm{COO}, \text { asym }}$, respectively, while


polysaccharide rings [25]. Similarly, the HC sample showed typical bands of a Ca-Al LDHs with a Friedel's salt structure, including bands at $3636 \mathrm{~cm}^{-1}$ corresponding to $v_{\mathrm{OH}}$ of water molecules, $3475 \mathrm{~cm}^{-1}$ ( $v_{\mathrm{OH}}$ of hydroxyl groups of the layers), and $1610 \mathrm{~cm}^{-1}$ (bending $v_{\mathrm{HOH}}$ of water), while the bands at wavenumber values below $1100 \mathrm{~cm}^{-1}$ were attributed to $v_{\mathrm{MO}}$ and $v_{\mathrm{MOM}}$ lattice modes of the layers $[17,26]$. Finally, the wide band at $1446 \mathrm{~cm}^{-1}$ was attributed to carbonate ions, incorporated as an impurity to the solid due to the basic $\mathrm{pH}$ conditions during the synthesis procedure [27]. Finally, the FT-IR spectra of CaAlg/HC beads showed bands of both alginate $\left(v_{\mathrm{COO} \text {,sym }}\right.$ and $v_{\mathrm{COO} \text {,asym }}$ as well as $v_{\mathrm{COC}, \text { sym }}$ and $v_{\mathrm{COC}, \text { asym }}$ modes at $1613,1421,1089$, and $1033 \mathrm{~cm}^{-1}$, respectively) and $\mathrm{HC}\left(v_{\mathrm{OH}}\right.$ at 3648 and $3489 \mathrm{~cm}^{-1}, v_{\mathrm{MO}}$ and $v_{\mathrm{MOM}}$ lattice modes below $\left.1100 \mathrm{~cm}^{-1}\right)$.

The TG/DTA curves (Figure 3) completed the study of CaAlg-HC interactions and allowed establishment of estimations on the chemical composition of the beads. The TGA curve of CaAlg beads showed a first weight loss up to a residual mass (\%M) of $87.4 \%$, associated with a wide endothermic effect in the DTA curve, centered at around $80^{\circ} \mathrm{C}$, which was attributed to dehydration of the CaAlg beads. Two main weight losses associated with exothermic effects centered at 280 and $650{ }^{\circ} \mathrm{C}$, attributed to the oxidation of the alginate chains, were registered at larger $\mathrm{T}$ values. The $\% \mathrm{M}$ at $800{ }^{\circ} \mathrm{C}$ was $22.9 \%$, which was consistent with a $\left(\mathrm{C}_{6} \mathrm{H}_{8} \mathrm{O}_{6}\right)_{2} \mathrm{Ca} \cdot 3.1 \mathrm{H}_{2} \mathrm{O}$ formula, if $\mathrm{CaO}$ was considered the main residue of the thermal decomposition of the beads (the water content was estimated based on the dehydration mass loss). 


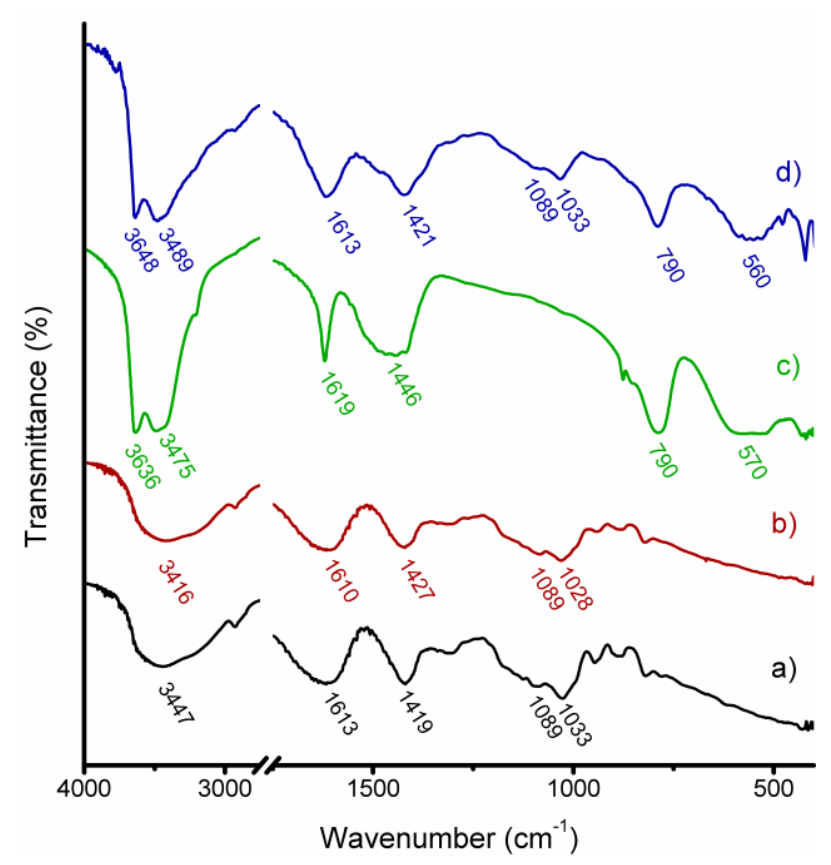

Figure 2. FT-IR spectra of (a) NaAlg, (b) CaAlg beads, (c) HC, (d) CaAlg/HC beads.
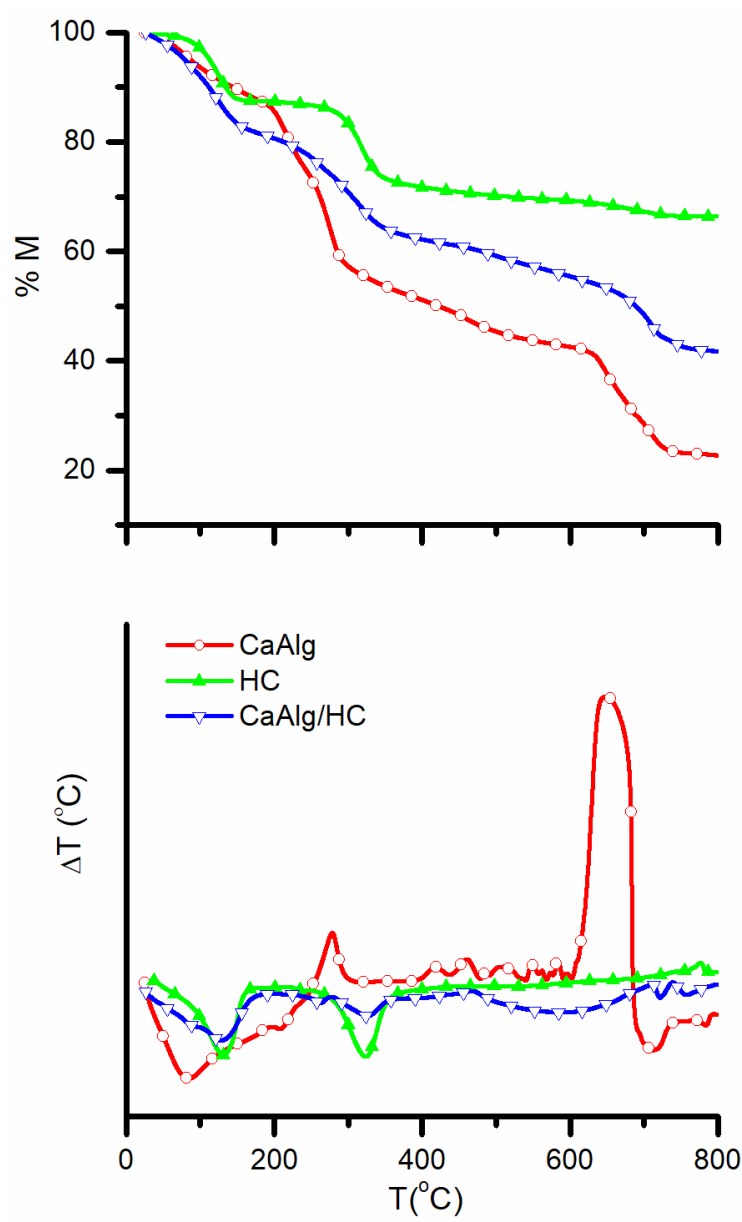

Figure 3. TG/DTA curves of HC powder as well as CaAlg and CaAlg/HC beads.

On the other hand, $\mathrm{HC}$ showed a dehydration mass loss up to $\% \mathrm{M}=87.3 \%$, associated with an endothermic peak centered at $130^{\circ}$. The mass loss was produced in a narrower $\mathrm{T}$ range than for 
CaAlg, as corresponds to the larger crystallinity of HC. The second weight loss was attributed to the dehydroxylation and interlayer anion loss [19], $\% \mathrm{M}$ reaching $65.9 \%$ at $800{ }^{\circ} \mathrm{C}$. The mass losses obtained were fitted well with the presence of a phase of a $\mathrm{Ca}_{2} \mathrm{Al}(\mathrm{OH})_{6} \mathrm{Cl} \cdot 2 \mathrm{H}_{2} \mathrm{O}$ like that proposed in the JCPDS file 31-0105, considering mayemite $\left(\mathrm{Ca}_{12} \mathrm{Al}_{14} \mathrm{O}_{33}\right)$ and $\mathrm{CaO}$ as the main residues at $800{ }^{\circ} \mathrm{C}$ [28].

Finally, $\mathrm{CaAlg} / \mathrm{HC}$ beads exhibited a dehydration step whose shape, both in the TGA and DTA curves, seemed to combine those of $\mathrm{HC}$ and CaAlg. The $\% \mathrm{M}$ after this step was smaller $(81.9 \%)$ than for $\mathrm{HC}$ and $\mathrm{CaAlg}$, which indicated that $\mathrm{HC}$ inclusion in the beads produced a larger hydration of the polymer and/or the particles. At larger $\mathrm{T}$ values, the endothermic peak corresponding to the dihydroxylation and interlayer anion loss observed for $\mathrm{HC}$ was maintained for $\mathrm{CaAlg} / \mathrm{HC}$. However, the exothermic effects corresponding to the oxidation of the alginate chains observed for the CaAlg beads vanished and only a wide and weak endothermic band was observed in the $450-700{ }^{\circ} \mathrm{C}$ range. The $\% \mathrm{M}$ value at $800{ }^{\circ} \mathrm{C}$ was $42.1 \%$, intermediate between those of $\mathrm{HC}$ and $\mathrm{CaAlg}$, which was concordant with the 1.25:1 NaAlg to HC ratio of the dispersion used for bead formation.

The SEM images of HC (Figure 4a) portrayed the typical lamellar morphology of the particles of Friedel's salts [18] and a wide particle size distribution, although the particles mostly showed irregular borders, resembling the hexagonal symmetry of the unit cell. An EDS chemical analysis was performed for this sample, obtaining a $\mathrm{Ca} / \mathrm{Al}$ ratio of $2.0 \pm 0.1$, quite concordant with the chemical composition of the Ca-Al LDH registered in JCPDS file 31-0105. On the other hand, the cross-sections of CaAlg beads showed only waves and wrinkles but neither particles or porosity were present [1,29]. Finally, the sections of the CaAlg/HC beads showed the presence of particles with a lamellar morphology, like those obtained for $\mathrm{HC}$ and, consequently, the cross-section of the beads presented a rougher surface than pure $\mathrm{CaAlg}$ beads.

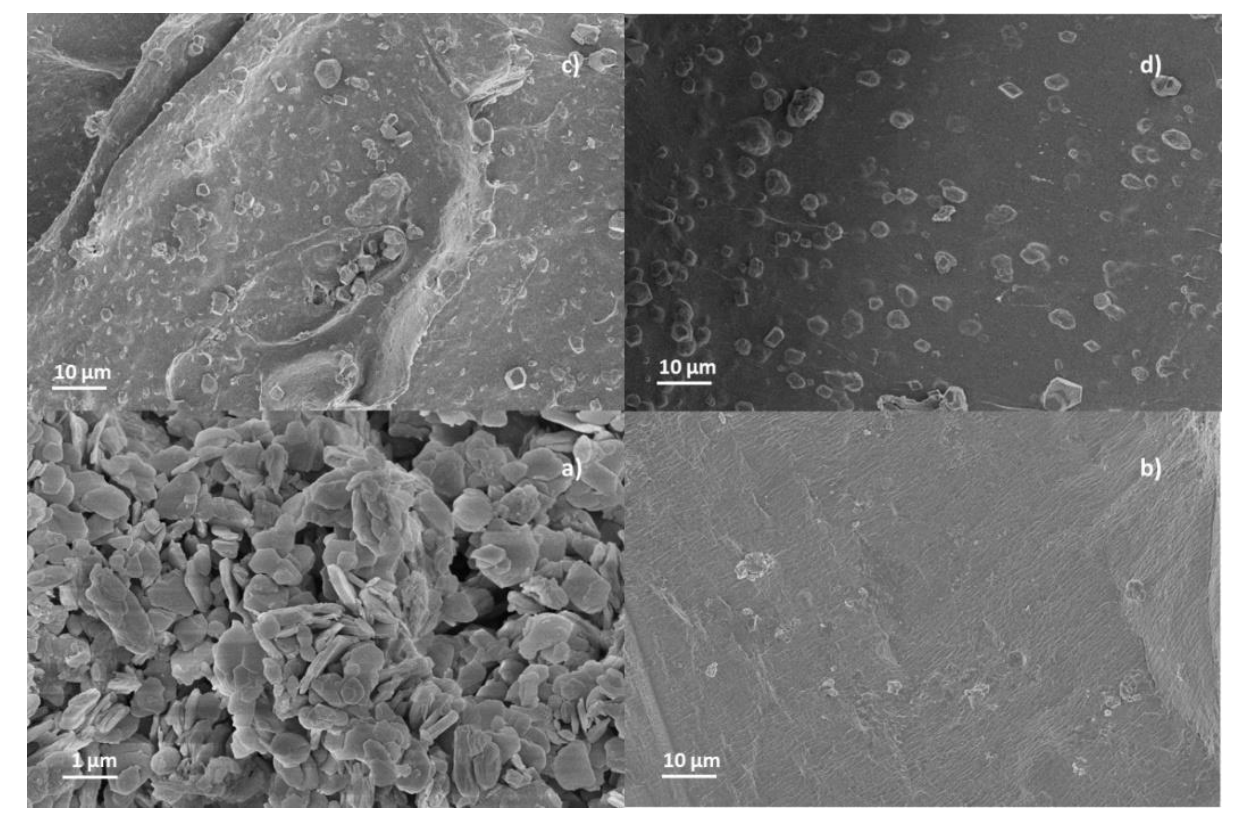

Figure 4. SEM images of (a) HC, (b) AlgCa beads, (c) and (d) CaAlg/HC beads.

\subsection{Proton Uptake Kinetics}

The $\mathrm{pH}$ buffering capacity of $\mathrm{CaAlg}$ and $\mathrm{CaAlg} / \mathrm{HC}$ (Figure 5) were studied as a base to explain their heavy metal uptake capacity. pH plays a major role in heavy metal uptake by alginate beads, as the main uptake mechanism is the coordinate binding by carboxylate groups, whose deprotonation ratio is determined by the $\mathrm{pH}$ of the medium [30]. Additionally, the removal capacity of HC is based on its acid base buffering capacity, which leads to an increase in the $\mathrm{pH}$ of the polluted medium, and the precipitation of the corresponding heavy metal hydroxides $[9,17]$. The $\mathrm{pH}$ vs $\mathrm{t}$ curves indicated that $\mathrm{CaAlg}$ beads (Figure 5a) presented buffering capacity at $\mathrm{pH}$ values lower than 5 , which was in 
good accord with carboxylate as the main proton uptake agent. The final $\mathrm{pH}$ decreased with increasing $[\mathrm{HCl}]$ in all cases, which indicated that the carboxylate groups of alginate portrayed a wide range of $\mathrm{pKa}$ values. The $\mathrm{AlgCa} / \mathrm{HC}$ beads (Figure $5 \mathrm{c}$ ) presented larger final $\mathrm{pH}$ values than $\mathrm{AlgCa}$ for every $[\mathrm{HCl}]$, which was related to the acid base reactivity of HC. Previous works showed that Ca-Al LDHs are dissolved at $\mathrm{pH}$ values lower than 11 [9], and the dissolution kinetics of $\mathrm{HC}$ powder, performed in the same conditions as the beads (Supporting Information, Figure S2), led to final pH values of up to 9.5 for the lowest $[\mathrm{HCl}]$ value, which were reached in less than one minute. Then, $\mathrm{HC}$ inclusion in CaAlg beads allowed control of the proton release rate while increasing the buffering capacity of alginate.
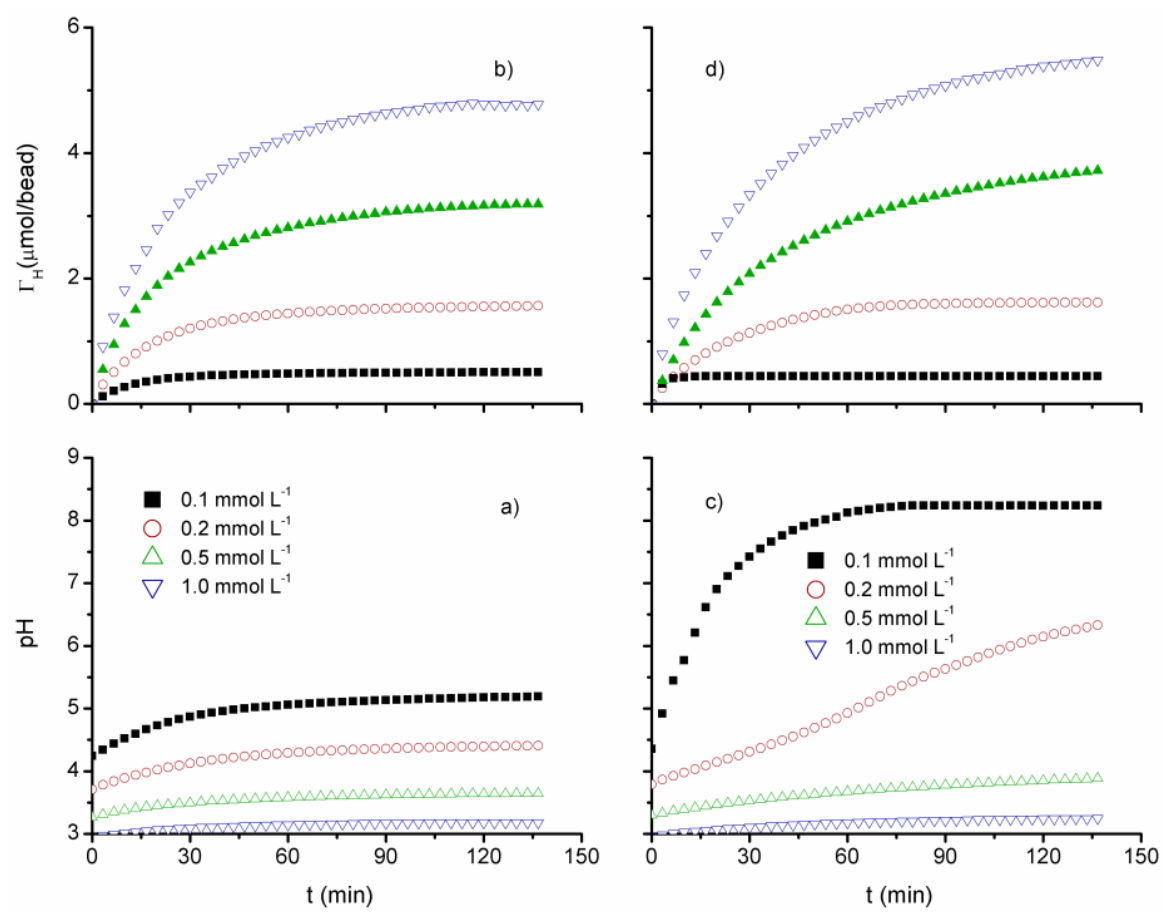

Figure 5. $\mathrm{pH}$ vs $\mathrm{t}$ curves $(\mathbf{a}, \mathbf{c})$ and proton uptake $\left(\Gamma_{\mathrm{H}}\right)$ kinetics $(\mathbf{b}, \mathbf{d})$ for $\mathrm{AlgCa}(\mathbf{a}, \mathbf{b})$ and $\mathrm{AlgCa} / \mathrm{HC}$ beads (10 units) placed in $100 \mathrm{~mL}$ solutions of increasing [HCl]. One out of 20 points are represented in the curves.

The proton uptake $\left(\Gamma_{\mathrm{H}}\right)$ vs $\mathrm{t}$ curves of both CaAlg and CaAlg/HC beads (Figure $5 \mathrm{~b}, \mathrm{~d}$, respectively) showed a proton uptake capacity at the end of the measured range $\left(\Gamma_{\mathrm{H}, 150}\right)$ that increased with increasing $[\mathrm{HCl}] . \Gamma_{\mathrm{H}, 150}$ values were similar for both at low $[\mathrm{HCl}]$ values but, at $[\mathrm{HCl}]$ larger than $0.5 \mathrm{mmol} \cdot \mathrm{L}^{-1}, \Gamma_{\mathrm{H}, 150}$ values were larger for $\mathrm{CaAlg} / \mathrm{HC}$ than for CaAlg. Proton uptake was exclusively due to protonation of carboxylate groups in the case of $\mathrm{CaAlg}$ beads. On the other hand, the proton uptake by $\mathrm{CaAlg} / \mathrm{HC}$ beads at the lowest $[\mathrm{HCl}]$ values was exclusively due to $\mathrm{HC}$ dissolution, as the $\mathrm{pH}$ values in the experiment were considerably higher than the pKa values reported for this biopolymer [3]. As $[\mathrm{HCl}]$ values increased and final $\mathrm{pH}$ values decreased, the contribution of carboxylate protonation processes increased. Consequently, HC dissolution and carboxylate protonation were additive at the two highest $[\mathrm{HCl}]$ values and the proton uptake by $\mathrm{CaAlg} / \mathrm{HC}$ beads was higher than for CaAlg beads. The $\Gamma_{\mathrm{H}}$ vs $t$ curves were fitted with different kinetic models, including zero order and Higuchi models (see Section 2.4), but the best fits were obtained for the latter one in all cases. Consequently, only the fitting parameters of this model are included in Table 1, while the fitting parameters of the zero order model are included as supporting information (Table S1). The good fit obtained for this model indicated that the proton uptake rate was mainly controlled by the diffusion of protons or hydroxyls across the bead. The origin of coordinate $\left(\Gamma_{0}\right)$ values were near zero and even slightly negative, which indicated that there was no initial proton uptake due to fast processes that were not included in the 
main dissolution mechanism, contrary to that observed for LDHs in dispersion [14]. The $\mathrm{k}_{\mathrm{D}}$ values were quite similar for $\mathrm{AlgCa}$ and $\mathrm{CaAlg} / \mathrm{HC}$ beads at the same $[\mathrm{HCl}]$ value, which indicated that the kinetic behavior was mainly controlled by the CaAlg network. Both beads showed increasing $\mathrm{k}_{\mathrm{D}}$ values with increasing [ $\left.\mathrm{HCl}\right]$, which is a typical dependence for increasing concentration of one of the reactants in diffusion controlled reactions [21,31]. The only exception for these trends was the fitting of $\mathrm{CaAlg}$ beads at the lowest concentration, which showed a larger $\mathrm{k}_{\mathrm{D}}$ value than that of CaAlg. This effect was attributed to the high reactivity of $\mathrm{HC}$, which was, as previously described, mainly responsible for the proton uptake at this $[\mathrm{HCl}]$.

Table 1. Fitting constants of proton uptake kinetics according to the diffusion model.

\begin{tabular}{ccccccccc}
\hline Beads & \multicolumn{3}{c}{ AlgCa } \\
\hline$[\mathrm{HCl}]^{\mathrm{a}}$ & $\Gamma_{\mathrm{H}, 150} \mathrm{~b}$ & $\Gamma_{\mathrm{H}, 0} \mathrm{~b}$ & $\mathrm{k}_{\mathrm{D}}{ }^{\mathrm{d}}$ & $\mathrm{R}^{2}$ & $\Gamma_{\mathrm{H}, 150} \mathrm{~b}$ & $\Gamma_{\mathrm{H}, 0} \mathrm{~b} / \mathrm{HC}$ & $\mathrm{k}_{\mathrm{D}}{ }^{\mathrm{d}}$ & $\mathrm{R}^{2}$ \\
0.1 & 0.5 & -0.07 & 0.10 & 0.997 & 0.5 & -0.07 & 0.21 & 0.997 \\
0.2 & 1.6 & -0.16 & 0.26 & 0.999 & 1.6 & -0.19 & 0.24 & 0.999 \\
0.5 & 3.2 & -0.30 & 0.49 & 0.997 & 3.9 & -0.33 & 0.44 & 0.997 \\
1.0 & 4.8 & -0.38 & 0.70 & 0.998 & 5.6 & -0.39 & 0.67 & 0.999 \\
\hline \multicolumn{3}{c}{${ }^{\mathrm{a}} \mathrm{mmol} \mathrm{L}^{-1},{ }^{\mathrm{b}} \mu \mathrm{mol} \mathrm{bead}^{-1}{ }^{\mathrm{c}} \mathrm{min}^{\mathrm{d}} \mu \mathrm{mol} \mathrm{min}^{-1 / 2} \mathrm{bead}^{-1}$}
\end{tabular}

\section{3. $\mathrm{Cu}^{2+}$ Removal Tests}

The $\mathrm{Cu}^{2+}$ uptake capacity $\left(\Gamma_{\mathrm{Cu}}\right)$ of the beads was evaluated as a function of the $\mathrm{Cu}^{2+}$ concentration at equilibrium ([Cu$]_{\text {eq }}$, Figure 6). The $\mathrm{pH}$ kinetics of the solutions were also followed to obtain further information about the uptake mechanism. Both CaAlg beads and $\mathrm{HC}$ powder presented $\mathrm{Cu}^{2+}$ uptake capacity by themselves (Figure 6A), but the former presented a lower affinity for $\mathrm{Cu}^{2+}$ ions than the latter. Nevertheless, it was enough to produce a removal effectivity $\left(\% \mathrm{R}=[\mathrm{Cu}]_{\mathrm{eq}} /[\mathrm{Cu}]_{\text {ini }}\right)$ near $80 \%$ at $[\mathrm{Cu}]_{\text {ini }}$ values around $3 \mathrm{ppm}$, which led to $[\mathrm{Cu}]_{\mathrm{eq}}$ values below those recommended by the US Environmental Protection Agency for tap water [32]. The fitting of the curves using the Langmuir equation led to $\Gamma_{\mathrm{Cu} \text {, max }}$ and $\mathrm{K}_{\mathrm{L}}$ values similar (Table 2) to those found by other authors $[1,7,8]$. Heavy metal incorporation by CaAlg beads was produced by interaction with carboxylate and hydroxyl groups of the polymer chains, preferably to carboxylate groups of the mannuronate blocks, which do not participate in the binding of $\mathrm{Ca}^{2+}$ ions [23]. The $\mathrm{pH}$ of the medium was maintained below 6.2 in all cases, which indicated that $\mathrm{CaAlg}$ beads were not producing a significant formation of $\mathrm{Cu}$ hydroxides.

On the other hand, HC showed a high capacity and affinity for $\mathrm{Cu}^{2+}$, which reduced the concentration of these anions below the detection limit until the plateau was abruptly reached. This high affinity allowed a $\% \mathrm{R}=99 \%$ at $[\mathrm{Cu}]_{\text {ini }}=3 \mathrm{ppm}$. This high affinity was related to the large buffering capacity of $\mathrm{HC}$ at high $\mathrm{pH}$ values, as reflected in the $\mathrm{pH}$ vs $\mathrm{t}$ curves (Figure $5 \mathrm{c}$. Inset). These curves showed final $\mathrm{pH}$ values above 8 , reached in less than 30 seconds, for points placed in the section where the $[\mathrm{Cu}]_{\text {eq }}$ was nearly zero (points $\mathrm{i}-\mathrm{iii}$ ). Once the buffering capacity of $\mathrm{HC}$ was exhausted (point iv), the $\mathrm{pH}$ of the medium was equilibrated at values around 6 and the curve abruptly reached a plateau. These high $\Gamma_{\mathrm{Cu} \text {,max }}$ and $\mathrm{K}_{\mathrm{L}}$ values were similar to those obtained previously for $\mathrm{Cu}^{2+}$ ions removal by hydrocalumite $[9,17]$. This maximum capacity was consistent with the total substitution of $\mathrm{Ca}^{2+}$ ions by $\mathrm{Cu}^{2+}$ ions, obtaining a $\mathrm{Cu}-\mathrm{Al} \mathrm{LDH}$ as final product [9].

$\mathrm{CaAlg} / \mathrm{HC}$ beads showed advantages and disadvantages compared to their separate components. The $\mathrm{pH}$ curves for these beads showed a great $\mathrm{pH}$ increase, which was slowed down by the inclusion in the alginate beads. This $\mathrm{pH}$ increase indicated that precipitation of $\mathrm{Cu}(\mathrm{OH})_{2}$ was produced. Regrettably, this precipitation was produced outside the $\mathrm{CaAlg} / \mathrm{HC}$ beads, as deduced from the turbidity of the supernatants, which was detected visually. In order to confirm and quantify $\mathrm{Cu}(\mathrm{OH})_{2}$ precipitation outside the beads, $[\mathrm{Cu}]_{\text {eq }}$ were determined before and after filtration of the equilibrated medium. The non-filtered medium contained the formed $\mathrm{Cu}(\mathrm{OH})_{2}$, which was dissolved after dilution on $0.1 \mathrm{~mol} \cdot \mathrm{L}^{-1}$, while with the filtered medium, only the remaining free $\mathrm{Cu}^{2+}$ ions were included. 

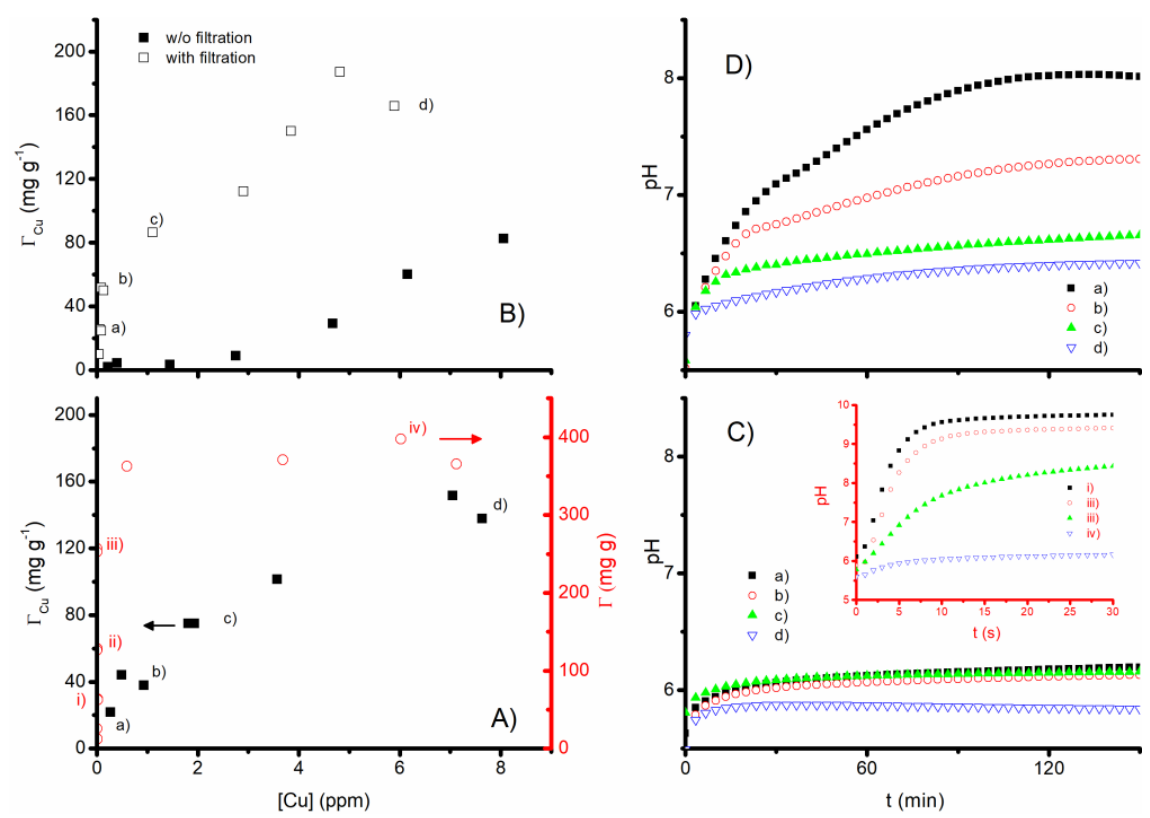

Figure 6. $\mathrm{Cu}^{2+}$ uptake isotherms of (A) AlgCa (left axis, filled squares) and HC (right axis, void circles) (B) $\mathrm{AlgCa} / \mathrm{HC}$ beads, with and without filtration of the supernatants after bead removal. $\mathrm{pH}$ kinetics during the uptake experiment with (C) AlgCa beads and HC (Inset), (D) AlgCa/HC. Every pH kinetic curve presented a correspondence with a point of the isotherm that was marked in the corresponding curve in layers A and B.

Table 2. Fitting parameters of $\Gamma_{\mathrm{Cu}}$ vs $[\mathrm{Cu}]_{\text {eq }}$ using the Langmuir model.

\begin{tabular}{cccc}
\hline Sample & $\boldsymbol{\Gamma}_{\mathbf{C u}, \max }(\mathbf{m g} / \mathbf{g})$ & $\mathbf{K}_{\mathbf{L}}\left(\mathbf{p p m}^{-\mathbf{1}}\right)$ & $\mathbf{R}^{\mathbf{2}}$ \\
\hline CaAlg & 191 & 0.24 & 0.941 \\
HC & 382 & 16.48 & 0.998 \\
$\mathrm{CaAlg} / \mathrm{HC}$ & 190 & 0.99 & 0.946 \\
\hline
\end{tabular}

The curve before filtration (filled squares) showed that negligible uptake was produced by the beads at low $[\mathrm{Cu}]_{\text {eq, }}$, while the curve after filtration showed a drastic $\Gamma_{\mathrm{Cu}}$ increase at $[\mathrm{Cu}]_{\text {eq }}$ near zero, similar to that found for $\mathrm{HC}$. $\mathrm{Cu}^{2+}$ ions were then completely removed from the medium and precipitated as $\mathrm{Cu}(\mathrm{OH})_{2}$ outside the beads due to the HC buffering capacity. In good accord, the curves of points a) and b) showed equilibrium $\mathrm{pH}$ values above 7 , although they were reached in longer times than for $\mathrm{HC}$. At $[\mathrm{Cu}]_{\text {eq }}$ larger than $3 \mathrm{ppm}$, the curves obtained for non-filtrated medium showed a significant $\Gamma_{\mathrm{Cu}}$ increase. This increase was parallel to a decreasing slope of the curves obtained after filtration, which, together with the diminution of the equilibrium $\mathrm{pH}$ below 6.5, indicated that the capacity of $\mathrm{HC}$ to buffer the $\mathrm{pH}$ of the medium was exhausted. Consequently, the mechanism of $\mathrm{Cu}^{2+}$ uptake by metal hydroxide precipitation was complemented by the metal ion complexation by carboxylate groups of alginate. This mechanism seemed not to be exhausted in the measurement range, but the fitting of the curve obtained after filtration indicated that the uptake capacity of $\mathrm{CaAlg} / \mathrm{HC}$ beads was like that of CaAlg beads while the affinity increased. Nevertheless, the precipitation of $\mathrm{Cu}(\mathrm{OH})_{2}$ was a clear disadvantage for the usage of $\mathrm{HC}$ containing CaAlg beads as $\mathrm{Cu}^{2+}$ scavengers.

\section{Conclusions}

Calcium alginate ( $\mathrm{CaAlg}$ ) beads containing particles of a $\mathrm{Ca}-\mathrm{Al}$ layered double hydroxide with hydrocalumite structures (HCs) were prepared. The obtained beads $(\mathrm{CaAlg} / \mathrm{HC})$ showed good dispersion of the HC particles, which interacted with the carboxylate groups of the alginate chains. Pure CaAlg beads showed proton uptake capacity due to the protonation capacity of carboxylate groups of alginate, which was complemented, in the case of $\mathrm{CaAlg} / \mathrm{HC}$ beads, by the buffering 
capacity of HC particles. Conversely, the inclusion of these particles in the beads allowed the control of their reactivity, the equilibration times increasing from a few seconds for the HC powder to more than $60 \mathrm{~min}$ for the $\mathrm{CaAlg} / \mathrm{HC}$ beads. These beads showed a diffusive proton uptake kinetics either for pure CaAlg or HC containing beads. Both CaAlg and HC presented $\mathrm{Cu}^{2+}$ uptake capacity by themselves, but their combination did not merge the easy separation of the former with the high affinity of the latter. Despite the fact that the buffering capacity of the $\mathrm{HC}$ included in $\mathrm{CaAlg} / \mathrm{HC}$ beads produced an effective precipitation of $\mathrm{Cu}(\mathrm{OH})_{2}$ and CaAlg provided additional $\mathrm{Cu}^{2+}$ capacity, the heavy metal hydroxide was formed outside the beads, which hindered its separation. Nevertheless, inclusion of LDHs in CaAlg beads stands as an easy strategy to modify the reactivity of LDHs in environmental and pharmaceutical applications, among others.

Supplementary Materials: The following are available online at http://www.mdpi.com/2305-7084/3/1/22/s1: Figure S1 Images of the calcium alginate beads, either pure or containing Ca-Al; Figure S2, $\mathrm{pH}$ vs $\mathrm{t}$ curves and proton uptake kinetics for HC; Table S1, Fitting constants of proton uptake kinetics according to the zero order model.

Author Contributions: R.R. and A.B. conceived and designed the experiments; A.B. performed the experiments; R.R. and A.B. analyzed the data; R.R. contributed reagents/materials/analysis tools; R.R. wrote the paper.

Funding: This research was funded by SeCyT-UNC, project number 05/C585; FON-CyT, project numbers 12/0634; and CONICET, PIP 11220120100575.

Acknowledgments: SEM images were recorded at the Laboratorio de Microscopía Electrónica y Análisis porRayos X (LAMARX).

Conflicts of Interest: The authors declare no conflict of interest.

\section{References}

1. Sun, J.; Chen, Y.; Yu, H.; Yan, L.; Du, B.; Pei, Z. Removal of $\mathrm{Cu}^{2+}, \mathrm{Cd}^{2+}$ and $\mathrm{Pb}^{2+}$ from aqueous solutions by magnetic alginate microsphere based on $\mathrm{Fe} 3 \mathrm{O} 4 / \mathrm{MgAl}$-layered double hydroxide. J. Colloid Interface Sci. 2018, 532, 474-484. [CrossRef] [PubMed]

2. Alcantara, A.C.S.; Aranda, P.; Darder, M.; Ruiz-Hitzky, E. Bionanocomposites based on alginate-zein/layered double hydroxide materials as drug delivery systems. J. Mater. Chem. 2010, 20, 9495-9504. [CrossRef]

3. El Rouby, W.M.A. Efficient water decontamination using layered double hydroxide beads nanocomposites. Environ. Sci. Pollut. Res. 2018. Available online: https://doi.org/10.1007/s11356-018-3257-7 (accessed on 27 February 2019).

4. Kim Phuong, N.T. Entrapment of Mg-Al layered double hydroxide into alginate/polyvinyl alcohol beads for water remediation. J. Environ. Chem. Eng. 2014, 2, 1082-1087. [CrossRef]

5. Lee, K.Y.; Mooney, D.J. Alginate: Properties and biomedical applications. Prog. Polym. Sci. 2012, 37, 106-126. [CrossRef] [PubMed]

6. Rocher, V.; Siaugue, J.-M.; Cabuil, V.; Bee, A. Removal of organic dyes by magnetic alginate beads. Water Res. 2008, 42, 1290-1298. [CrossRef] [PubMed]

7. Benettayeb, A.; Guibal, E.; Morsli, A.; Kessas, R. Chemical modification of alginate for enhanced sorption of $\mathrm{Cd}(\mathrm{II}), \mathrm{Cu}(\mathrm{II})$ and $\mathrm{Pb}$ (II). Chem. Eng. J. 2017, 316, 704-714. [CrossRef]

8. Wang, $\mathrm{F}$; $\mathrm{Lu}, \mathrm{X}$.; $\mathrm{Li}$, X.Y. Selective removals of heavy metals $\left(\mathrm{Pb}^{2+}, \mathrm{Cu}^{2+}\right.$, and $\left.\mathrm{Cd}^{2+}\right)$ from wastewater by gelation with alginate for effective metal recovery. J. Hazard. Mater. 2016, 308, 75-83. [CrossRef] [PubMed]

9. Rojas, R. Copper, lead and cadmium removal by Ca Al layered double hydroxides. Appl. Clay Sci. 2014, 87, 254-259. [CrossRef]

10. Rojas, R. Effect of particle size on copper removal by layered double hydroxides. Chem. Eng. J. 2016, 303, 331-337. [CrossRef]

11. Pérez, M.R.; Pavlovic, I.; Barriga, C.; Cornejo, J.; Hermosín, M.C.; Ulibarri, M.A. Uptake of $\mathrm{Cu}^{2+}, \mathrm{Cd}^{2+}$ and $\mathrm{Pb}^{2+}$ on $\mathrm{Zn}-\mathrm{Al}$ layered double hydroxide intercalated with edta. Appl. Clay Sci. 2006, 32, 245-251. [CrossRef] 
12. Pavlovic, I.; Pérez, M.; Barriga, C.; Ulibarri, M.A. Adsorption of $\mathrm{Cu}^{2+}, \mathrm{Cd}^{2+}$ and $\mathrm{Pb}^{2+}$ ions by layered double hydroxides intercalated with the chelating agents diethylenetriaminepentaacetate and meso-2,3-dimercaptosuccinate. Appl. Clay Sci. 2009, 43, 125-129. [CrossRef]

13. Kameda, T.; Hoshi, K.; Yoshioka, T. Uptake of $\mathrm{Sc}^{3+}$ and $\mathrm{La}^{3+}$ from aqueous solution using ethylenediaminetetraacetate-intercalated $\mathrm{Cu}-\mathrm{Al}$ layered double hydroxide reconstructed from $\mathrm{Cu}-\mathrm{Al}$ oxide. Solid State Sci. 2011, 13, 366-371. [CrossRef]

14. Parello, M.L.; Rojas, R.; Giacomelli, C.E. Dissolution kinetics and mechanism of Mg-Al layered double hydroxides: a simple approach to describe drug release in acid media. J. Colloid Interf. Sci. 2010, 351, 134-139. [CrossRef] [PubMed]

15. Liang, X.; Zang, Y.; Xu, Y.; Tan, X.; Hou, W.; Wang, L.; Sun, Y. Sorption of metal cations on layered double hydroxides. Colloids Surfaces A Physicochem. Eng. Asp. 2013, 433, 122-131. [CrossRef]

16. Zhang, J.; Zhao, H.; Cao, H.; Li, H.; Li, Z. Removal of $\mathrm{Cd}^{2+}$ from water by Friedel's salt (FS: $3 \mathrm{CaO} \cdot \mathrm{A1}_{2} \mathrm{O}_{3} \cdot \mathrm{CaCl}_{2} \cdot 10 \mathrm{H}_{2} \mathrm{O}$ ): Sorption characteristics and mechanisms. J. Environ. Sci. (China) 2013, 25, 1719-1725. [CrossRef]

17. Milagres, J.L.; Bellato, C.R.; Vieira, R.S.; Ferreira, S.O.; Reis, C. Preparation and evaluation of the Ca-Al layered double hydroxide for removal of copper(II), nickel(II), zinc(II), chromium(VI) and phosphate from aqueous solutions. J. Environ. Chem. Eng. 2017, 5, 5469-5480. [CrossRef]

18. Guo, Q.; Tian, J. Removal of fluoride and arsenate from aqueous solution by hydrocalumite via precipitation and anion exchange. Chem. Eng. J. 2013, 231, 121-131. [CrossRef]

19. Li, D.; Guo, X.; Tian, Q.; Xu, R.; Xu, Z.; Zhang, J. Dearsenization of caustic solution by synthetic hydrocalumite. Hydrometallurgy 2016, 161, 1-6. [CrossRef]

20. Rojas, R.; Jimenez-Kairuz, A.F.; Manzo, R.H.; Giacomelli, C.E. Release kinetics from LDH-drug hybrids: Effect of layers stacking and drug solubility and polarity. Colloids Surfaces A Physicochem. Eng. Asp. 2014, 463, 37-43. [CrossRef]

21. Costa, P.; Sousa Lobo, J.M. Modeling and comparison of dissolution profiles. Eur. J. Pharm. Sci. 2001, 13, 123-133. [CrossRef]

22. Li, L.; Qu, W.; Zhang, X.; Lu, J.; Chen, R.; Wu, F.; Amine, K. Succinic acid-based leaching system: A sustainable process for recovery of valuable metals from spent Li-ion batteries. J. Power Sources 2015, 282, 544-551. [CrossRef]

23. Papageorgiou, S.K.; Katsaros, F.K.; Kouvelos, E.P.; Nolan, J.W.; Le Deit, H.; Kanellopoulos, N.K. Heavy metal sorption by calcium alginate beads from Laminaria digitata. J. Hazard. Mater. 2006, 137, 1765-1772. [CrossRef] [PubMed]

24. Lalhmunsiama; Pawar, R.R.; Hong, S.M.; Jin, K.J.; Lee, S.M. Iron-oxide modified sericite alginate beads: A sustainable adsorbent for the removal of $\mathrm{As}(\mathrm{V})$ and $\mathrm{Pb}(\mathrm{II})$ from aqueous solutions. J. Mol. Liq. 2017, 240, 497-503. [CrossRef]

25. Etcheverry, M.; Cappa, V.; Trelles, J.; Zanini, G. Montmorillonite-alginate beads: Natural mineral and biopolymers based sorbent of paraquat herbicides. J. Environ. Chem. Eng. 2017, 5, 5868-5875. [CrossRef]

26. Kloprogge, J.T.; Frost, R.L. Infrared and Raman Spectroscopic Studies of Layered Double Hydroxides (LDHs). In Layered Double Hydroxides: Present and Future; Rives, V., Ed.; Nova Science Publishers: Hauppauge, NY, USA, 2001; pp. 139-192.

27. Jia, Y.; Wang, H.; Zhao, X.; Liu, X.; Wang, Y.; Fan, Q.; Zhou, J. Kinetics, isotherms and multiple mechanisms of the removal for phosphate by Cl-hydrocalumite. Appl. Clay Sci. 2016, 129, 116-121. [CrossRef]

28. Zheng, L.; Xia, S.; Lu, X.; Hou, Z. Transesterification of glycerol with dimethyl carbonate over calcined Ca-Al hydrocalumite. Cuihua Xuebao/Chinese J. Catal. 2015, 36, 1759-1765. [CrossRef]

29. Ren, H.; Gao, Z.; Wu, D.; Jiang, J.; Sun, Y.; Luo, C. Efficient Pb(II) removal using sodium alginate-carboxymethyl cellulose gel beads: Preparation, characterization, and adsorption mechanism. Carbohydr. Polym. 2016, 137, 402-409. [CrossRef] [PubMed]

30. Veglio, F.; Esposito, A.; Reverberi, A.P. Copper adsorption on calcium alginate beads: Equilibrium pH-related models. Hydrometallurgy 2002, 65, 43-57. [CrossRef] 
31. Felderhof, B.U.; Deutch, J.M. Concentration dependence of the rate of diffusion-controlled reactions. J. Chem. Phys. 1976, 64, 4551-4558. [CrossRef]

32. United States Environmental Protection Agency Lead and Copper Rule (LCR), 56 FR. 1991; pp. 26460-26564. Available online: https: / / nepis.epa.gov / Exe/ZyPDF.cgi?Dockey=60001N8P.txt (accessed on 27 February 2019). 